\title{
SPACE CHARGE ACCUMULATION UNDER THE EFFECTS OF TEMPERATURE GRADIENT ON SOLID DIELECTRIC DC CABLE
}

\author{
W. Choo, G. Chen and S. G. Swingler \\ School of Electronics and Computer Science, \\ University of Southampton, Highfield, Southampton, SO17 1BJ, United Kingdom \\ *Email: ctc05r@ecs.soton.ac.uk
}

\begin{abstract}
It is well known that existence and accumulation of space charge within the insulating material poses threat to the reliability in the operation of dc power cables. When the cables are loaded under high voltage direct current (HVDC), temperature gradient is developed across the insulation material. In this paper, commercial ac XLPE power cables were used under an application voltage of $80 \mathrm{kV}$ dc with different temperature gradients loaded between the insulating material. Space charge distributions were then measured across the insulation of the cable by means of a modified pulsed electroacoustic (PEA) system with a current transformer attached. Therefore, a replica of a power cable under load conditions could be obtained, which allows us to investigate the formation, migration and accumulation of space charges in a power cable both without and with different temperature gradients consideration across the bulk of the insulating material. Discussion will be made thoroughly in order to understand the space charge phenomenon of power cable under its service temperature.
\end{abstract}

\section{INTRODUCTION}

There is a worldwide demand for electricity, which is growing annually in every developing country. Efficient HVDC underground transmission cables are employed to offer high power rating and stability with reduced transmission losses due to the requirements for bulk transmission and factors such as network stability, environmental considerations and transmission deregulatory policies. Polymeric power cables consisting cross-linked polyethylene (XLPE) as the insulating material are used in such transmission system. The XLPE material has excellent high dielectric strength and electrical resistivity in combination with excellent physical properties such as resistance to cracking and moisture penetration, but shows performance limits under $\mathrm{dc}$ application particularly in the presence of space charge [1].

These space charges are generated when a high electric field is applied on the insulating material, where charges are injected at the electrodes or through ionisation of impurities within the bulk of the material $[2,3]$. This accumulation of comprehensive immobile charge carrier in the material, which is superimposed to the laplacian field will result in the changes of load of the dielectric material, which in turn accelerate the aging to premature breakdown of the material itself.

In general, the dynamics of space charge injection/accumulation depend significantly on the electric field and the temperature. Therefore, to understand the nature and dynamics of space charge accumulation phenomenon within the XLPE polymeric material used in power cable under its service temperature. A modified PEA system with a current transformer attached is employed to perform the space charge measurement across the insulating material of the power cable with and without temperature gradient consideration within its insulation.

\section{EXPERIMENTAL SETUP}

\subsection{Modified PEA System}

The schematic diagram for the newly modified PEA system with current transformer attached for the measurement of space charge in coaxial cable is illustrated below in Figure 1.

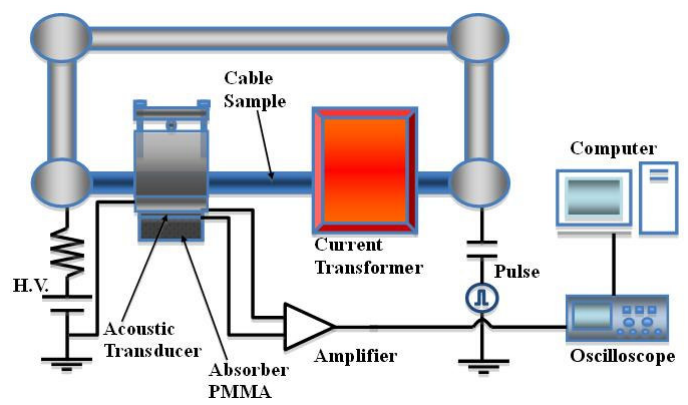

Figure 1: Illustration of a Modified PEA System with Current Transformer for Cable.

From the above figure, we can see that the coaxial cable lies flatly in close contact with the flat ground aluminium (Al) electrode in the PEA system and running through the current transformer with the ends of the cable cores attached to a HVDC supply and an electrical pulse generator respectively. Once in operation, the temperature gradient within the insulation material is obtained by the current transformer through induction heating, which heats up the cable. Further details of the PEA technique and the 
basic principles can be found in numerous publications [4-6].

\subsection{Test configuration}

Two appropriate test setups were arranged for the measurements under ambient temperature of $\sim 18^{\circ} \mathrm{C}$, one is without temperature gradient within the insulation, and the other is with temperature gradient consideration.

The samples used in this paper were obtained from commercial $11 \mathrm{kV}$ ac XLPE insulated power cables (inner radii $=5.8 \mathrm{~mm}$; outer radii $=9.2 \mathrm{~mm}$; insulation thickness $=3.4 \mathrm{~mm}$ ). Degassing process was not applied on the cable samples; therefore, the insulation material contains cross-linking by-products.

For the cable samples having a conductor of $95 \mathrm{~mm}^{2}$ stranded aluminium in cross section and with a $3.4 \mathrm{~mm}$ thickness of XLPE as the insulating material, a stabilised temperature gradient of $10^{\circ} \mathrm{C}$ is obtained by having a $\sim 55^{\circ} \mathrm{C}$ temperature at its inner semiconductor and $\sim 45^{\circ} \mathrm{C}$ at its outer semiconductor and a $20^{\circ} \mathrm{C}$ temperature gradient is obtained from having a $\sim 89^{\circ} \mathrm{C}$ temperature at its inner insulation and $\sim 69^{\circ} \mathrm{C}$ at its outer insulation. Both $10^{\circ} \mathrm{C}$ and $20^{\circ} \mathrm{C}$ temperature gradients are obtained through an ac current of $250 \mathrm{~A}$ and $350 \mathrm{~A}$ respectively across the insulation after 2 hours of induced current heating, where the outer semiconductor of the cable is cooled through natural convection cooling by the ambient temperature. After obtaining the stabilised temperature gradient desired, the cable is then stressed at $80 \mathrm{kV}$ for a total of 9 hours where space charge measurements with poling voltage on and off were taken at a time interval of an hour.

\section{EXPERIMENTAL RESULTS AND DISCUSSION}

The voltage on and off space charge profiles of the asreceived cable sample under ambient temperature are presented in Figure 2 (a) and (b). As can be seen from Figure 2 (a), large amount of heterocharge build up is obtained in the XLPE insulation adjacent to the anode (inner electrode) after the first hour of poling and positive charges tends to accumulate after 3 hours around the middle of the sample towards the cathode (outer electrode). The rapid accumulation rate of negative charge within the sample can be explained as negative charge is much easier being trapped as compared to positive charge. It is evident by looking at the relatively higher rate of increase of negative space charge in each cable sample before they start to be cancelled out by the positive charge. Other reasons could be more negative charge is injected into the samples than positive charge or it could be a combination of both.

For the build up of positive charge around the middle of the sample is due to the difficulty of trapping positive charge and consequently these positive charges will not be trapped in the vicinity of the anode but rather will be attracted to the cathode vicinity where it is cancelled out or recombines with the accumulated negative charge.

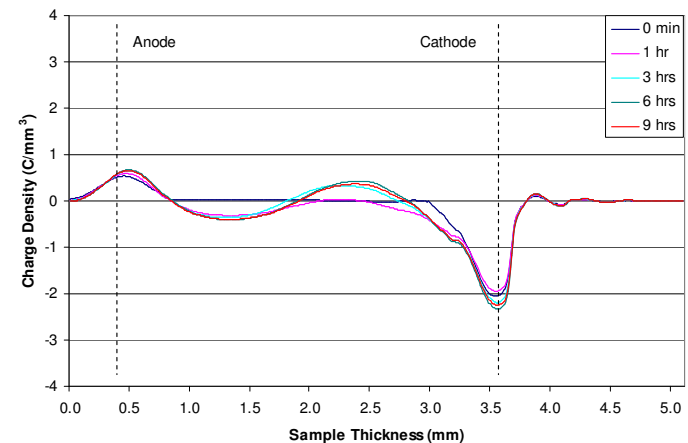

(a) Volts on

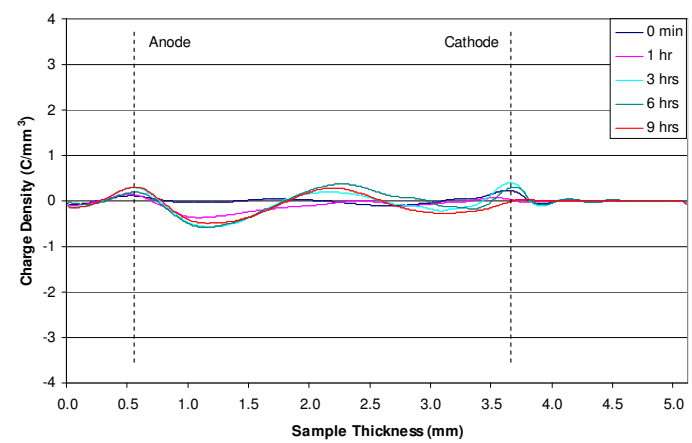

(b) Volts off

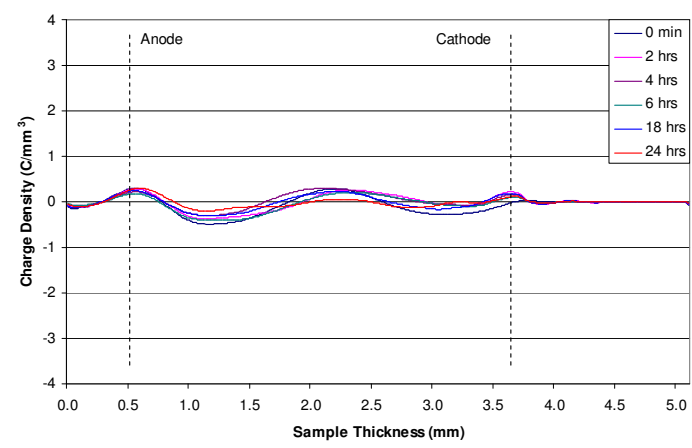

(c) Space charge decay

Figure 2: Space charge profiles for (a) volts on, (b) volts off and (c) decay at ambient temperature with $\mathrm{T}_{\text {outer }}=\sim 18^{\circ} \mathrm{C}$

Therefore, both negative and positive magnitude increase significantly with the duration of the applied voltage and will stabilise after around 20 hours [7]. In the volts off measurement as shown in Figure 2 (b), most charges being trapped across the insulation are slow moving charges, where 
portions of negative slow moving charges are trapped at the vicinity across the electrodes and slow moving positive charges in the middle of the sample.

With both electrodes short-circuited after the removal of the application voltage after 9 hours of stressing. The space charge decay profile shown in Figure 2 (c), shows a very slow decay rate between the 24 hours of decaying, where small portion of negative charges adjacent to both electrodes and positive charge at the middle of the bulk are still visible across the sample after 24 hours.

Through replicating a power cable under load condition, a temperature gradient of $10^{\circ} \mathrm{C}$ across the insulating material results in Figure 3 (a) shows that only negative charges are formed initially at the first hour across the sample and the largest concentration of negative charges are located at the vicinity adjacent to the anode. It can be also observed that positive charge injection behaviour is shown at the vicinity of the anode. As it clearly shows that positive charges are attracted to the cathode vicinity where it cancels out or recombines with the accumulated negative charges, which shows a decrease in negative charges adjacent to both electrodes.

After 3 hours of application voltage, heterocharge starts to form at the vicinity adjacent to the cathode and this positive charge increases with the duration of application voltage. In the volts off measurement in Figure 3 (b), only packets of slow moving negative are trapped across the sample, where the main portion of negative charges spread between the anode vicinity to the middle of the sample and small packets of it are visible from the middle of the sample to the cathode vicinity. In the charge decaying profile with $10^{\circ} \mathrm{C}$ temperature gradient, the charges show a quick decay rate, which the charges almost diminish in 2 hours after the removal of applied voltage.

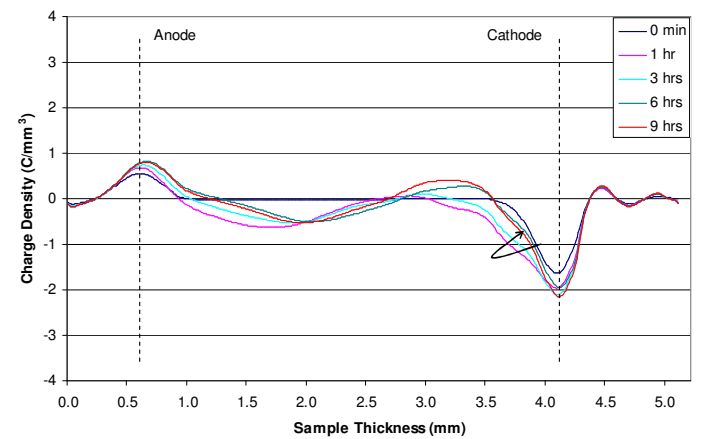

(a) Volts on

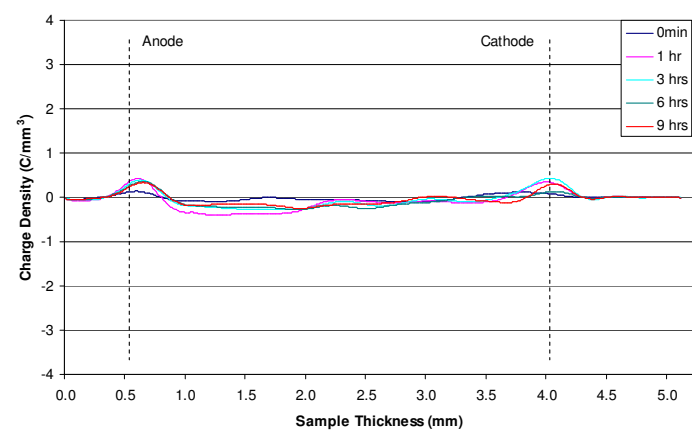

(b) Volts off

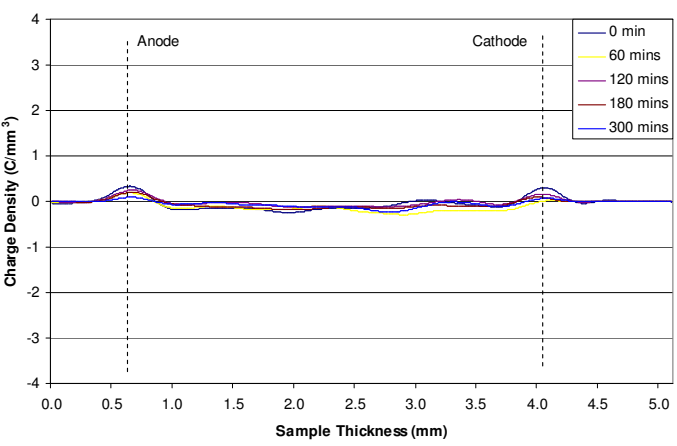

(c) Space charge decay

Figure 3: Space charge profiles for (a) volts on, (b) volts off and (c) decay with $10^{\circ} \mathrm{C}$ temperature gradient and with $\mathrm{T}_{\text {outer }}=\sim 45^{\circ} \mathrm{C}$.

At a temperature gradient of $20^{\circ} \mathrm{C}$ across the insulating material, the results obtained are illustrated in Figure 4. With comparison to the result of Figure 4 (a) and $10^{\circ} \mathrm{C}$ temperature result in Figure 3 (a), it shows that with an increase in temperature gradient the amount of charges do increase across the sample material. Figure 4 (b) also tend to show that slow moving positive charge are now visible at the vicinity adjacent to the cathode after 3 hours, which there was no sign of slow moving positive charges in both the voltage off profiles of ambient temperature and $10^{\circ} \mathrm{C}$ temperature gradient in Figures 2 (b) and 3 (b) respectively. The decay rate was extremely rapid when $20^{\circ} \mathrm{C}$ temperature gradient across the sample material as shown in Figure 4 (c), where the charges was diminished within an hour. 


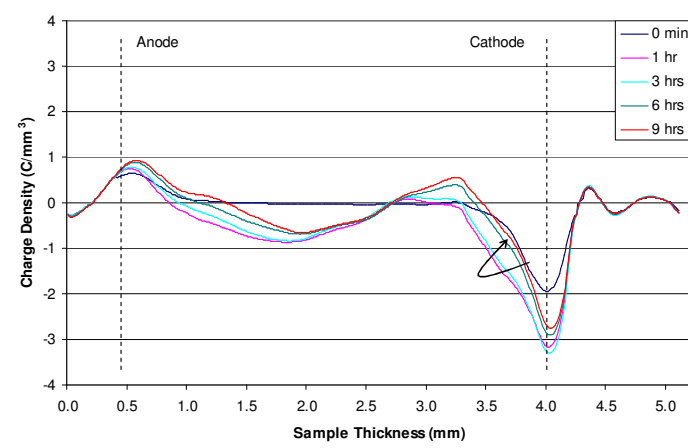

(a) Voltage on

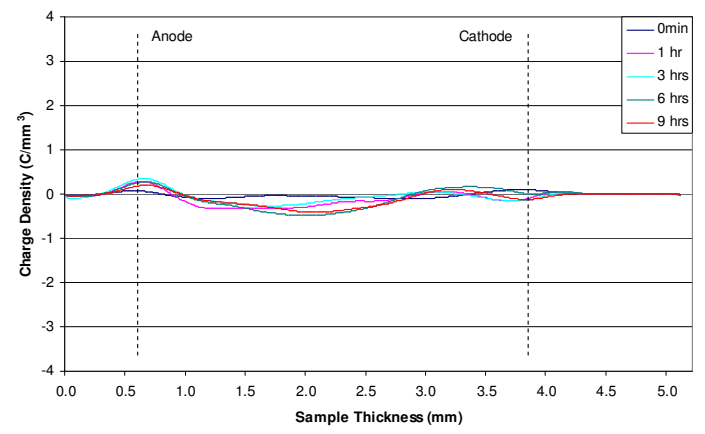

(b) Voltage off

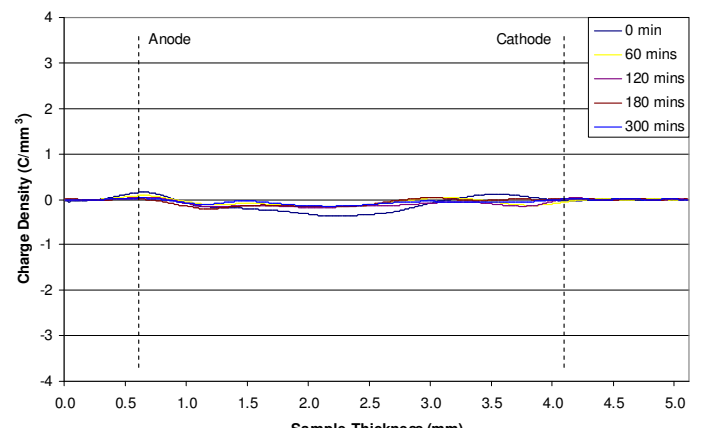

(c) Space charge decay

Figure 4: Space charge profiles for (a) volts on, (b) volts off and (c) decay with $20^{\circ} \mathrm{C}$ temperature gradient and with $\mathrm{T}_{\text {outer }}=\sim 69^{\circ} \mathrm{C}$.

In accordance to the theory, the build up of the induced charges on the cathode should lead to a decrease in negative charges or an increase of positive charges adjacent to the outer electrode. Surprisingly, however, with the increasing temperature gradient, the electrode adjacent negative charges decrease in the company of the induced charges on the cathode as shown in Figure 4 (a) with comparison with both Figure 2 (a) and 3 (a). Specifically, the charge very close to the cathode is decreasing, while the space charges closer to the middle of the sample seem to be more consistent.
This phenomenon could not be explained from simple electromagnetic theory. In view of the fact that the decrease with temperature is limited to the area close to the colder electrode and interface phenomenon were not included in the theory.

The basic explanation for this phenomenon can be explained if we were to imagine that the cable insulation consists of a series of parallel capacitor and resistor connected under dc application and with the consideration of temperature gradient across the insulation material. The resistivity through the insulation material will increase across from the inner to the outer of the insulation material, when a temperature gradient exists. In addition, the formation of homocharge in the vicinity of the cathode results in the electric field reduction. The conductivity of an insulating material increases with the electric field. The lower electric field in this region leads to an increase in resistivity. As the voltage distribution under $\mathrm{dc}$ condition is governed by resistivity. Therefore, voltage drop across the region increases. This increased voltage drop can be reflected by increase in the amount of charge accumulated on the paralleled connected capacitor. This will lead to an increase in measured charge on the cathode. Similarly, if the homocharge moves away, the induced charge peak will decrease. This phenomenon is unique to the dc cable and become obvious with a higher temperature gradient.

\section{CONCLUSIONS}

In this paper we have measured space charge dynamics in XLPE power cable under ambient and different temperature gradients across the insulation material. The following conclusions may be drawn:

When existence of temperature gradient across the insulation material of a fully loaded $\mathrm{dc}$ cable is considered, additional complexity will be done on the space charge dynamics.

At higher temperature, the amount of injected charges is expected to be increased because the relative injection barrier is reduced. Accumulation of space charge is faster under temperature gradient. On the other hand, it may happen that by increasing the temperature of the cable insulation the charges will have a higher mobility and the neutralisation of space charge is also faster. Negative charge seems to be always faster than the positive charge at the same temperature. Therefore, it is clear that injection and transport of charges is enhanced upon temperature increase.

Finally, the present results show that space charge distributions in commercial XLPE cables with increasing temperature gradients across the insulating material cannot be fully explained with simple electromagnetic theory and further investigation are needed on the phenomena between the adjacent of the outer electrode and to the semi-con/insulation interface. 


\section{ACKNOWLEDGMENTS}

Grateful acknowledgement is made to Prysmian Cables $\&$ Systems for the contribution of the $11 \mathrm{kV}$ XLPE insulated power cables used in this research.

\section{REFERENCES}

[1] L. A. Dissado and J. H. Fothergill, Electrical degradation and breakdown in polymers, London, Peter Peregrinus Ltd, 1992.

[2] J. C. Fothergill, G. C. Montanari, G. C. Stevens, C. Laurent, G. Teyssedre, L. A. Dissado, U. H. Nilsson, G. Platbrood, "Electrical, Microstructural, Physical and Chemical Characterization of HV XLPE Cable Peelings for an Electrical Aging Diagnostic Data Base", IEEE Trans. on Dielectrics and Elect. Insul., Vol. 10, No. 3; June 2003.

[3] Y. Maeno, N. Hirai, Y. Ohki, T. Tanaka, M. Okashita, T. Maeno, "Effects of Crosslinking Byproducts on Space Charge Formation in Crosslinked Polyethylene", IEEE Trans. on Dielectrics and Elect. Insul., Vol. 12, No. 1; February 2005.

[4] T. Takada and T. Sakai, "Measurement of Electric Fields at a Dielectric/Electrode Interface Using an Acoustic Transducer Technique", IEEE Trans. On Elect. Insul., Vol. 18, No. 6, pp. 619-628, December 1983.

[5] K. Fukunaga, H. Miyata, M. Sugimori and T. Takada," Measurement of Charge Distribution in the Insulation of Cables Using Pulsed Electroacoustic Method," Trans. IEE japan, Vol. 110-A, No. 9, pp. 647-648, 1990.

[6] K. Fukunaga, H. Miyata, T. Takahaashi, S. Yoshida and T. Niwa, "Measurement of Space Charge Distribution in Cable Insulation Using the Pulsed Electroacoustic Method", Proceeding 3rd Int. Conf. on Polym. Insul. Power Cables, pp.520525, Versailles, France, 1991.

[7] M. Fu, G. Chen, L. A. Dissado and J. C. Fothergill, "Influence of Thermal Treatment and Residues on Space Charge Accumulation in XLPE for DC Power Cable Application", IEEE Trans. on Dielectr. Electr. Insul., Vol. 14, No.1; Feb 2007. 